\title{
Spitzenleistungen im Marketing erzielen
}

Sowohl in der Unternehmenspraxis als auch in der Marketingforschung ist oftmals von „Best Practice“-Unternehmen die Rede. Diese Unternehmen sind nicht nur überdurchschnittlich erfolgreich, sondern setzen häufig den Benchmark für die Konkurrenz. Doch warum sind Unternehmen wie Apple, Henkel, Nespresso oder Miele so erfolgreich? Was macht diese Unternehmen so besonders?

Das Ermitteln zentraler Erfolgs- und Wachstumsfaktoren ist eines der maßgeblichen Ziele angewandter Marketingforschung - auch wenn es sogar schwer fällt, einen einzigen, eindeutigen und unbestritten allgemeingültigen Erfolgsfaktor zu nennen. Die Stellhebel für nachhaltiges, profitables und risikoadäquates Wachstum sind vielmehr äußerst vielfältig und situativ.

Vor zwölf Jahren publizierte unser Institut ein Fallstudienbuch mit dem Titel „Best Practice in Marketing“. Für einige dieser Unternehmen war der Erfolg nicht von Dauer: Swissair, Porzellanfabrik Langenthal und die Verlagsgruppe Milchstraße stehen für Unternehmen, die Konkurs gingen oder zumindest ihre unternehmerische Selbstständigkeit verloren haben. Das berühmte Buch „In Search of Excellence“ von Tom Peters und Robert H. Waterman präsentierte Anfang der 80er Jahre eine Liste hocherfolgreicher Unternehmen, von denen insbesondere im High-Tech-Sektor viele kurze Zeit später alles andere als erfolgreich waren, beispielsweise Atari, Data General, DEC, Wang Labs und NCR. Dagegen hatte es General Electric damals nicht geschafft, auf die Erfolgsliste aufgenommen zu werden.

Doch welche sind nun die tatsächlichen Erfolgsfaktoren und -strategien im Marketing? Während sich einige Unternehmen auf ihre kundenfokussierte Innovationskraft konzentrieren, verlassen sich andere auf die emotionale Stärke ihrer Marke. Andere wiederum grenzen sich durch persönliche Kundenbeziehungen oder aber relevante Kundeninteraktion (Stichworte: Communities, Kundenintegration, Produktindividualisierung) von der Konkurrenz ab. Spitzenleistungen im Marketing bewegen sich letztlich immer im Spannungsfeld von Aktualität (Invention, Innovation, Erneuerung) und Kontinuität (Produkt- und Markenpflege, Kundenbindung). Erfolg führt allerdings häufig auch zu Sättigung und Trägheit, ermöglicht dadurch aber auch wieder den Erfolg anderer.

Diese Ausgabe der Marketing Review St. Gallen möchte Ihnen wertvolle Anregungen für Ihre Marketingerfolge liefern.

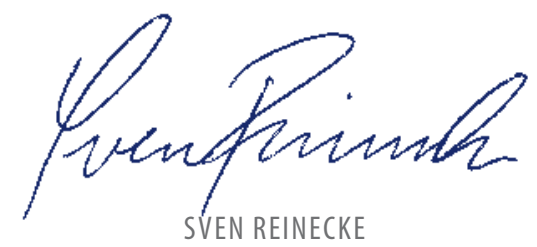

\section{Prof. Dr. Sven Reinecke}

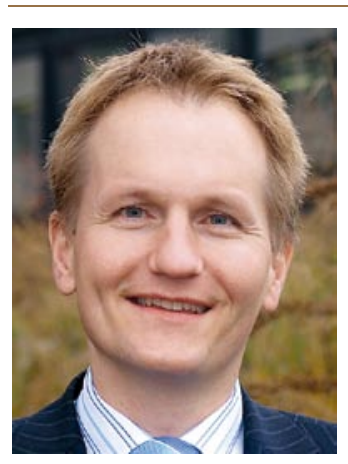

Direktor des Instituts für Marketing sowie Leiter des Kompetenzzentrums Marketing Performance Management an der Universität St. Gallen (CH). E-Mail: sven.reinecke@unisg.ch 